\title{
Research Article \\ Preparation of Luminescent Glass Aggregates from Soda-Lime Waste Glass
}

\author{
Vorrada Loryuenyong (iD) and Achanai Buasri (iD) \\ Department of Materials Science and Engineering, Faculty of Engineering and Industrial Technology, Silpakorn University, \\ Nakhon Pathom 73000, Thailand \\ Correspondence should be addressed to Vorrada Loryuenyong; vorrada@gmail.com
}

Received 19 July 2021; Revised 8 October 2021; Accepted 25 October 2021; Published 8 November 2021

Academic Editor: Regina De Fátima Peralta Muniz Moreira

Copyright (c) 2021 Vorrada Loryuenyong and Achanai Buasri. This is an open access article distributed under the Creative Commons Attribution License, which permits unrestricted use, distribution, and reproduction in any medium, provided the original work is properly cited.

\begin{abstract}
This research studied the preparation of luminescent glass aggregates prepared from soda-lime waste glass and strontium aluminate-based phosphors. The properties of the samples were determined by means of X-ray diffraction (XRD) technique, scanning electron microscopy (SEM), Archimedes' method, and photoluminescence (PL) spectroscopy. It was found that the pore characteristics, density, and formation of crystallite phases in the glassy matrix depended on the phosphor content. The addition of fine phosphor powder tended to inhibit the glass crystallization and to reduce the apparent porosity of the aggregates. In general, the disadvantage of phosphors is their luminescent degradation under thermal attacks, which limits their use in applications involving high-temperature annealing. The phosphors, however, still had good luminescent properties and long-term stability with the sintering temperature as high as $750^{\circ} \mathrm{C}$. The results indicated that the phosphors could be composited with glasses at high processing temperatures, enabling their widespread application.
\end{abstract}

\section{Introduction}

Glass is a very common material in our daily life. We have used glass in numerous applications including packaging for products, tableware, and construction. As a result, a million tons of glass waste have been generated annually. To conserve raw material resources, glass waste is usually recycled either by being remelted into glass products or reprocessed in various applications. For example, Bernardo et al. used glass waste to replace feldspar sand in the fabrication of glass ceramic stoneware [1]. The resultant products had high strength and high fracture toughness similar to those of conventional stoneware but required lower sintering temperatures. In addition, the use of glass waste also reduced the production costs of glass ceramics by reducing processing steps involving nucleation and crystal growth mechanisms [2].

Phosphors are materials that can emit intense and longlasting light when absorbing high external energy. They are widely used in many applications such as lighting and display devices $[3,4]$. Other applications include the use of glow-in-the-dark materials dispersed in self-luminescent cement-based composites [5]. The addition of particular types of phosphors such as strontium aluminate could provide long-lasting luminescence to the cement products. Despite this, it has been reported that the presence of phosphor powder could promote the hydration reaction of nonhydrated particles in cement, which enhanced the mechanical properties of the final products [5].

Phosphors could also be composited with other materials such as glasses [6], metals [7], or polymers [8] for energy-saving applications. The luminescence occurs when phosphors absorb the solar light during the day and illuminate at night. Although many applications of phosphor composites have been designed and commercially available, they normally suffer from thermal degradation when sintering at high temperatures $[9,10]$. This causes inferior luminescence and limits their use with high-temperature processing materials. Glass ceramics are materials with at least one crystalline phase dispersed in the glass. They are normally formed by the controlled crystallization of the glass. These materials have attracted tremendous attention due to their 
interesting properties including low thermal expansion, high stability, high mechanical strength, and high toughness. As a result, the incorporation of phosphors in glass ceramic matrix or phosphor-in-glass ceramics should produce luminescent materials with long-term stability, high durability, and long persistent luminescence. The major challenge, however, is to maintain the luminous efficiency of phosphors during the preparation processes at high temperatures.

In this study, luminescent or phosphor powder was added into the glass frits from soda-lime waste glass to fabricate glowing glass ceramic aggregates for energy-saving and eco-friendly construction materials. Strontium aluminate $\left(\mathrm{SrAl}_{2} \mathrm{O}_{4}\right)$-based phosphor, $\mathrm{SrAl}_{2} \mathrm{O}_{4}: \mathrm{Eu}^{2+}, \mathrm{Dy}^{3+}$, was used as a luminescent powder. This material has long persistent luminescence while also being affordable and nontoxic. It can be excited by a wide range of wavelengths of light to produce a blue-green glow, so the material can be charged under sunlight or strong indoor light. The advantages of phosphor materials coupled with economically favorable and environmentally friendly preparation methods could be beneficial for the development of luminescent aggregates or stones for architectural lighting with no electricity.

\section{Materials and Methods}

An experimental study was carried out to investigate the preparation of luminescent aggregates from the soda-lime glass waste obtained from soda water bottles (Singha Corporation, Thailand) and commercial $\mathrm{SrAl}_{2} \mathrm{O}_{4}$-based phosphor powder (45-55 $\mu \mathrm{m}$, fluorescent glow powder, Amhere Intertrade, Ltd., Thailand). Table 1 summarizes the chemical compositions of glass wastes and phosphor powders, in wt.\%, which were determined by an X-ray fluorescence spectrometer (ZSX Primus, Rigaku). The glass wastes were first cleaned, crushed, and grinded using ball-milling technique to obtain sand-like particles. The glass powder was then sieved into a particle size between 50 and $70 \mu \mathrm{m}$.

To prepare the aggregate mix, glass powder was mixed with phosphor powder at various amounts $(5 \%, 10 \%, 15 \%$, and $20 \%$ by total weight of the mixture), using an agate and pestle grinder. Since the glass powder could not well harden on its own, a small amount of inorganic binder was added. In this research, sodium silicate solution was added into the mixture at a binder/glass waste weight ratio of 1.00. The final mixture was then poured into a ballmolding machine to produce spherical-shaped phosphorin-glass aggregates. The samples were then sintered in air at $750^{\circ} \mathrm{C}$ for $30 \mathrm{~min}$ with a heating rate of $10^{\circ} \mathrm{C} / \mathrm{min}$.

The crystal structures of as-prepared luminescent glass aggregates were analyzed using an X-ray diffractometer with $\mathrm{CuK} \alpha$ radiation (XRD-6200, Shimadzu). Archimedes' method was used to calculate the bulk density and apparent porosity. The photoluminescence (PL) spectra of the samples were recorded using a spectrophotometer (AvaSpec2048TEC, Avantes). Microstructural images were studied through scanning electron microscopy (SEM, TM3030, Hitachi). Afterglow behaviour of luminescent aggregates was measured using an autoranging light meter (CEM, DT-1309).

\section{Results and Discussion}

Figure 1 shows XRD patterns of phosphor-in-glass ceramic aggregates with varying phosphor contents in comparison to bare phosphor sintered at $750^{\circ} \mathrm{C}$ for $30 \mathrm{~min}$. The XRD pattern of bare phosphor shows sharp characteristic peaks at $2 \theta=28.5^{\circ}, 29.4^{\circ}, 30.0^{\circ}$, and $35.2^{\circ}$, which agree well with the standard pattern of the monoclinic $\mathrm{SrAl}_{2} \mathrm{O}_{4}$ crystal structure (JCPDS PDF no. 00-028-1204). In our previous work [10], we found that phosphors had good structural stability at high temperatures up to $750^{\circ} \mathrm{C}$. The luminescent intensity was also optimized at this temperature due to the highest crystallinity of the phosphors, even though they might suffer from the oxidation of the luminescent center $\left(\mathrm{Eu}^{2+}, \mathrm{Dy}^{3+}\right)$.

For pure glass aggregates, the patterns show the appearance of crystalline peaks, which indicate the crystallization within the glassy matrix. The peaks are matched to the cristobalite $\left(\mathrm{SiO}_{2}\right)$ (JCPDS PDF no. 00-028-1204) and wollastonite $\left(\mathrm{CaSiO}_{3}\right)$ (JCPDS PDF no. 00-031-0300) crystals, which are consistent with previous reports $[11,12]$. In general, the crystallization of glass is obtained from the heat treatment processes. Based on previous researches $[10,13$, 14], the crystallization could be enhanced by impurities or surfaces of preexisting interfaces. As shown in Table 1, the major components of the glass frits used in this work are $\mathrm{SiO}_{2}, \mathrm{CaO}$, and $\mathrm{Na}_{2} \mathrm{O}$. Various other oxides with small quantities include $\mathrm{Al}_{2} \mathrm{O}_{3}, \mathrm{MgO}, \mathrm{Fe}_{2} \mathrm{O}_{3}, \mathrm{~K}_{2} \mathrm{O}$, and $\mathrm{TiO}_{2}$. It has been reported that a small amount of oxides such as $\mathrm{MgO}$ and $\mathrm{Al}_{2} \mathrm{O}_{3}$ in soda-lime glasses could induce the crystallization of devitrite $\left(\mathrm{Na}_{2} \mathrm{Ca}_{3} \mathrm{Si}_{6} \mathrm{O}_{16}\right)$, wollastonite $\left(\mathrm{CaSiO}_{3}\right)$, and $\mathrm{SiO}_{2}$ polymorphs [12]. The crystallization of these phases is normally a surface crystallization [12, 15], which may cause an increase in surface roughness and high porosity. With the addition of phosphor in the glassy matrix, the reverse effect is observed. The $\mathrm{SrAl}_{2} \mathrm{O}_{4}$-based phosphors could act as a network modifier and weaken the glass structure. The incorporation of $\mathrm{Sr}^{2+}$ and $\mathrm{Al}^{3+}$ from $\mathrm{SrAl}_{2} \mathrm{O}_{4}$ based phosphors in the glass structure inhibits the crystallization process of amorphous glasses, resulting in the degradation of the phosphor's structure. The cristobalite and wollastonite peaks, as a consequence, become weaker with the addition of phosphor powder. This is consistent with previous researches $[16,17]$.

Figure 2 shows the bulk density and apparent porosity of the samples. At low phosphor content, there is no significant change in the density of the samples, while their apparent porosity increases with increasing phosphor content. This is probably due to the surface crystallization and the inhibition of the viscous flow of glass particles by the presence of phosphor, thereby reducing the densification of the glasses and increasing the porosity. The nearly constant density is, therefore, the competition between the high density of crystalline phases, the low density of glassy phases, and the porous structure [18]. When the phosphor content increased to 15 and $20 \mathrm{wt} . \%$, however, both apparent porosity and bulk density are decreased. This could be because the crystallization of the glass is decreased, promoting the amorphous structure of the glass. It is found that the addition of a sufficient amount of phosphor could enhance the formation of 
TABLe 1: Chemical composition (wt.\%) of the glass and phosphor powders.

\begin{tabular}{lcccccccccc}
\hline Materials & \multicolumn{7}{c}{ Oxide (wt.\%) } & & & \\
\hline \multirow{3}{*}{ Glass frit } & $\mathrm{SiO}_{2}$ & $\mathrm{CaO}$ & $\mathrm{Na}_{2} \mathrm{O}$ & $\mathrm{Al}_{2} \mathrm{O}_{3}$ & $\mathrm{MgO}$ & $\mathrm{Fe}_{2} \mathrm{O}_{3}$ & $\mathrm{~K}_{2} \mathrm{O}$ & $\mathrm{SO}_{3}$ & $\mathrm{TiO}_{2}$ \\
& 68.618 & 17.485 & 8.863 & 2.170 & 1.930 & 0.284 & 0.224 & 0.192 & 0.103 \\
& $\mathrm{P}_{2} \mathrm{O}_{5}$ & $\mathrm{ZrO}_{2}$ & $\mathrm{SrO}$ & $\mathrm{PbO}$ & $\mathrm{ZnO}$ & $\mathrm{MnO}$ & & \\
& 0.032 & 0.052 & 0.019 & 0.012 & 0.005 & 0.011 & & \\
\multirow{5}{*}{ Phosphor } & $\mathrm{SrO}$ & $\mathrm{Al}_{2} \mathrm{O}_{3}$ & $\mathrm{P}_{2} \mathrm{O}_{5}$ & $\mathrm{SO}_{3}$ & $\mathrm{Dy}_{2} \mathrm{O}_{3}$ & $\mathrm{Eu}_{2} \mathrm{O}_{3}$ & $\mathrm{BaO}$ & $\mathrm{CaO}$ & $\mathrm{SiO}_{2}$ \\
& 63.025 & 16.833 & 11.394 & 7.259 & 1.135 & 0.820 & 0.154 & 0.112 & 0.048 \\
& $\mathrm{MgO}$ & $\mathrm{CuO}$ & $\mathrm{Ga}_{2} \mathrm{O}_{3}$ & & & & & \\
\hline
\end{tabular}
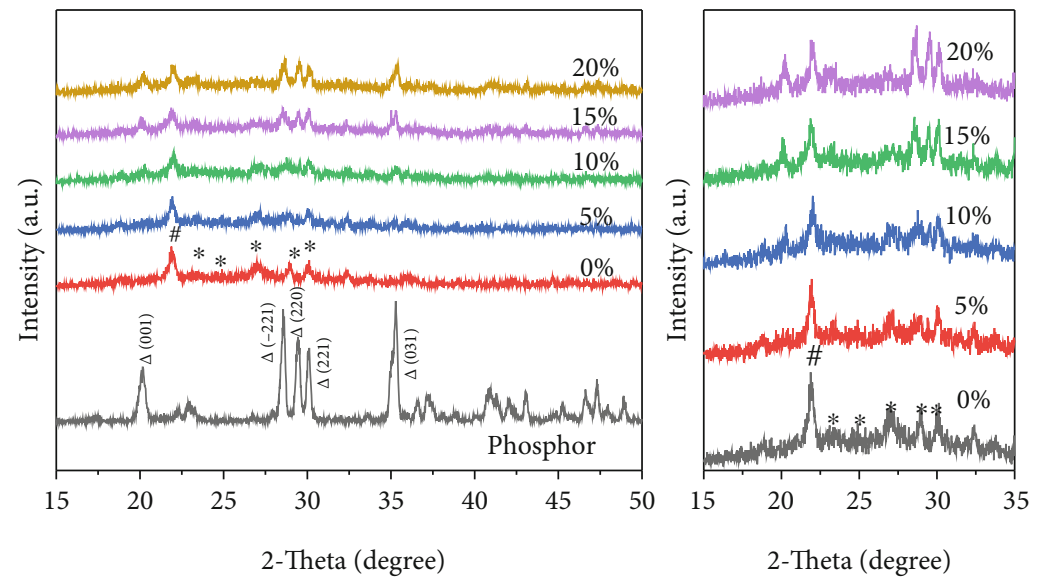

$$
\begin{aligned}
& \Delta=\mathrm{SrAl}_{2} \mathrm{O}_{4} \\
& *=\mathrm{CaSiO}_{3} \\
& \#=\mathrm{SiO}_{2}
\end{aligned}
$$

FIGURE 1: XRD patterns of bare phosphor and phosphor-in-glass ceramic aggregates with varying phosphor contents. The samples were sintered at $750^{\circ} \mathrm{C}$ for $30 \mathrm{~min}$. The image in (b) is a zoom for $\mathrm{CaSiO}_{3}$ and $\mathrm{SiO}_{2} \mathrm{XRD}$ peaks.
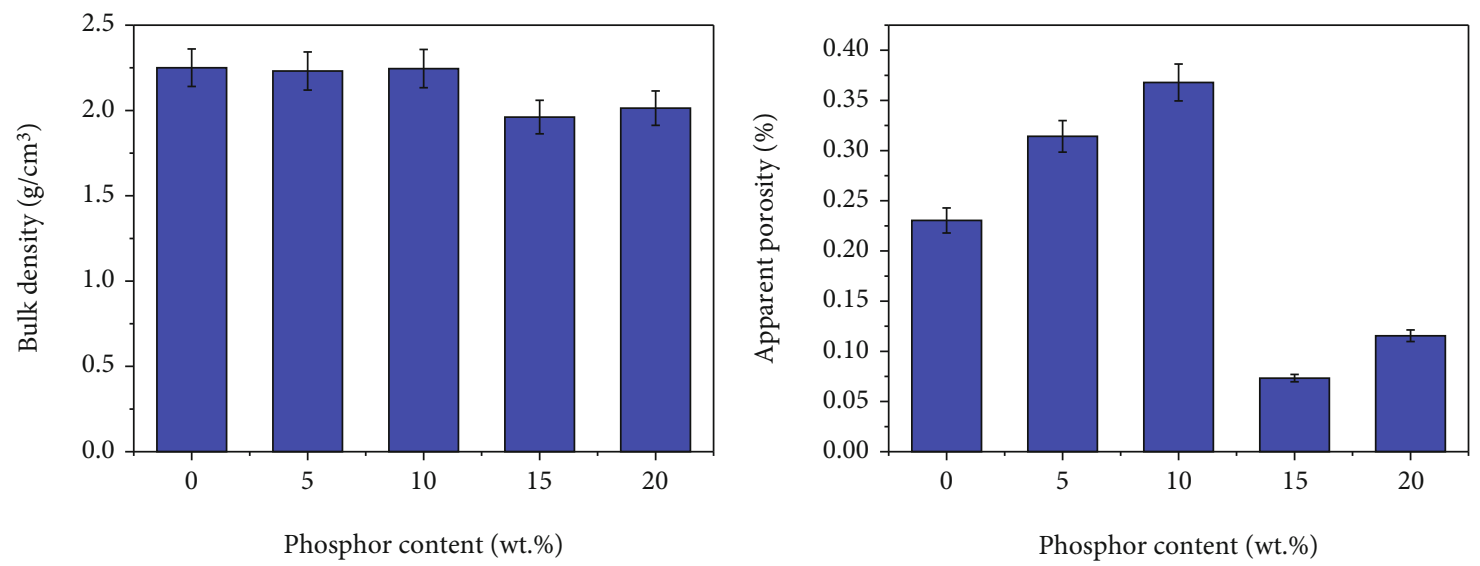

FIGURE 2: Bulk density and apparent porosity of phosphor-in-glass ceramic aggregates with varying phosphor contents.

the glassy phase. Similar observations have been previously reported that $\mathrm{SrAl}_{2} \mathrm{O}_{4}$-based phosphor could react with the matrix glass, causing the destruction of the $\mathrm{SrAl}_{2} \mathrm{O}_{4}$ structure $[16,19]$. This is consistent with the broader XRD peaks of the $\mathrm{SrAl}_{2} \mathrm{O}_{4}$ phase in glass aggregates, as shown in Figure 1 . The increase in porosity from $15 \%$ to $20 \%$ could be because an excessive amount of phosphor could act as a rigid inclusion, retarding the viscous sintering and densification process to occur properly. To study any dimensional changes of samples during heating, the samples were heated in a tube furnace at $750^{\circ} \mathrm{C}$, and pictures taken at different times were reported in Figure 3. It was found that all the 


\begin{tabular}{|c|c|c|c|c|c|c|}
\hline \multirow{2}{*}{$\begin{array}{c}\text { Phosphor } \\
\text { content } \\
\text { (wt.\%) }\end{array}$} & \multirow{2}{*}{$\begin{array}{r}\text { Initial } \\
\text { sample }\end{array}$} & \multicolumn{4}{|c|}{ During heat treatment } & \multirow{2}{*}{$\begin{array}{l}\text { After hea } \\
\text { treatmen }\end{array}$} \\
\hline & & $1 \mathrm{~min}$ & $10 \mathrm{~min}$ & $20 \mathrm{~min}$ & $30 \mathrm{~min}$ & \\
\hline 0 & & & & & & \\
\hline 5 & & & & & & \\
\hline 10 & & & & & & \\
\hline 15 & & & & & & \\
\hline 20 & & & & & & \\
\hline
\end{tabular}

Figure 3: Digital images of samples during the heat treatment at $750^{\circ} \mathrm{C}$ for $30 \mathrm{~min}$.
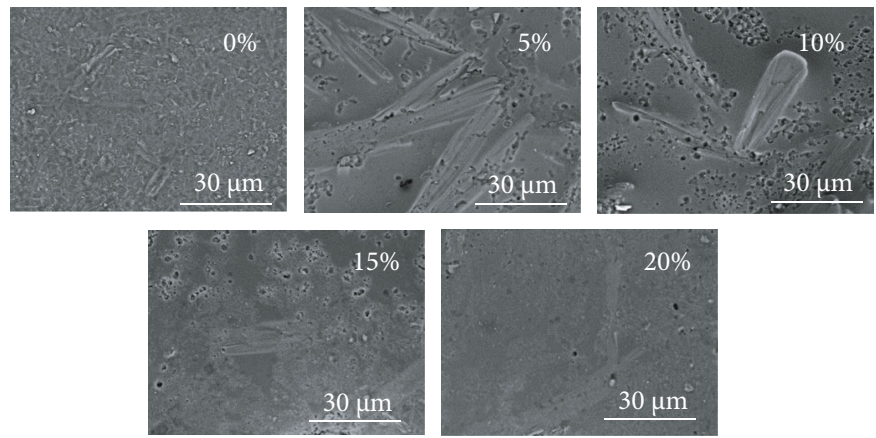

FIGURE 4: SEM micrograph of fractured surfaces of phosphor-in-glass ceramic aggregates with varying phosphor contents. The bar shows a $30 \mu \mathrm{m}$ scale. The samples were etched in HF solution for $30 \mathrm{~s}$.

samples did not experience any substantial shape changes. The heat treatment only caused a shrinkage due to the densification process. However, the degree of shrinkage tends to increase with increasing phosphor content.

The crystallization of the wollastonite phase in the glassy matrix could be confirmed from the microstructures of the samples (Figure 4). For 0 wt.\% phosphor content, the surface was rough with a number of pores randomly distributed in the glassy matrix. The presence of wollastonite, which occurred as rod-shaped crystals, could also be clearly seen. On the contrary, when phosphor powder was added, wollastonite crystals became larger in size but less in quantities. At a low phosphor/glass ratio, the grain growth might be restrained by the presence of the crystallite phases. It could also be observed that, with high phosphor concentration, the amounts of pores and crystalline phases were decreased in agreement with the previous discussion. To optimize the required properties of phosphor-in-glass ceramic aggregates, therefore, a suitable amount of glass frit and phosphor powder must be used.

PL spectra of luminescent glass aggregates with the excitation wavelength of $345 \mathrm{~nm}$ are displayed in Figure 5. For the sample with $0 \%$ phosphor, a small emission peak could be observed between 400 and $600 \mathrm{~nm}$. This peak could be obtained from the wollastonite crystals. Previous research

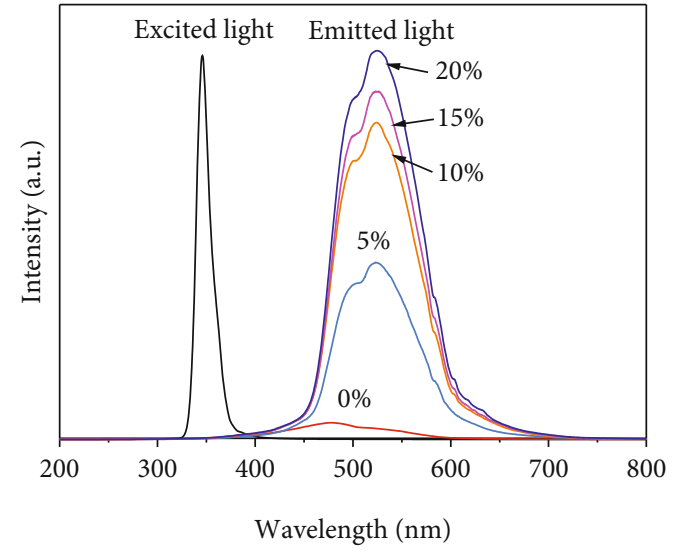

FIGURE 5: PL spectra of phosphor-in-glass ceramic aggregates with varying phosphor contents.

has reported that wollastonite could be a potential host for luminescent materials [20]. Their emission peaks could be between 350 and $800 \mathrm{~nm}$ depending upon its doping. For phosphor-in-glass ceramic aggregates, there is a dominant emission peak centered at $520 \mathrm{~nm}$, which could be assigned to the $4 \mathrm{f}^{6} 5 \mathrm{~d}^{1} \rightarrow 4 \mathrm{f}^{7}$ transition of $\mathrm{Eu}^{2+}$ in $\mathrm{SrAl}_{2} \mathrm{O}_{4}$. A shoulder peak is also observed at around $500 \mathrm{~nm}$. This could be due to 


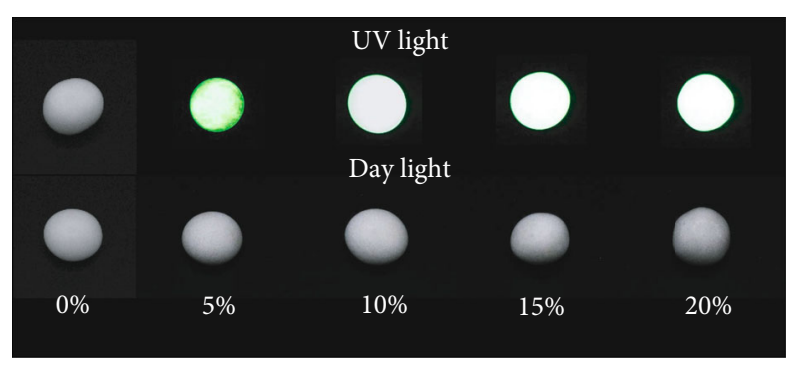

FIGURE 6: Phosphor-in-glass ceramic aggregates with varying phosphor contents with UV light exposure and in daylight.

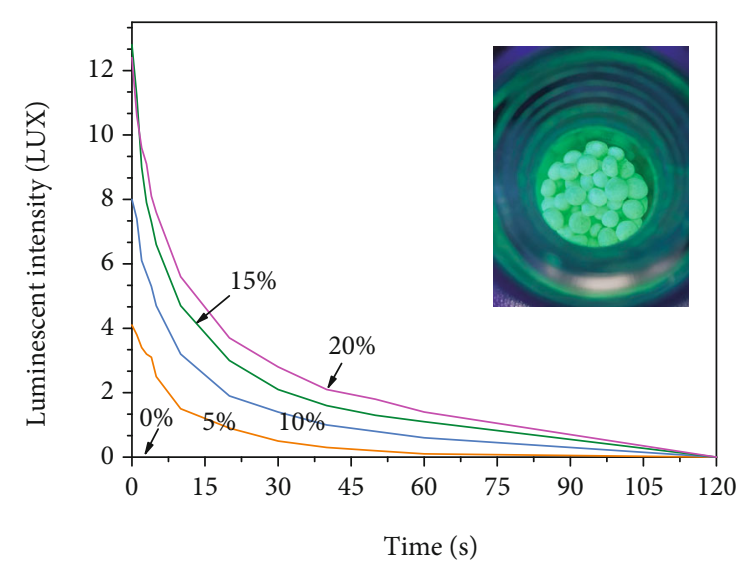

FIGURE 7: Luminescence decay curves of phosphor-in-glass ceramic aggregates with varying phosphor contents.

the crystal field splitting of the $\mathrm{Eu}^{2+}$. The $\mathrm{PL}$ intensity increased with increasing phosphor contents.

Figure 6 shows the physical appearance and the glowing effect of luminescent glass aggregates. The samples were exposed to UV light for $15 \mathrm{~min}$ to enable the glowing effect in the dark. With UV light exposure, the glass aggregates emitted a greenish glow. The glow was brighter with increasing phosphor content. The brightest apparent glow was observed in the sample with the highest phosphor content (20\%).

To study the afterglow duration time, the glass aggregates were exposed to UV light for $15 \mathrm{~min}$, and the luminescence intensity was measured with time, as shown in Figure 7. It could be seen that the photoluminescence of the samples exhibited fast initial decay. However, with full energy absorption from the UV light, the samples can produce a long greenish afterglow luminescence. In addition, the luminescence intensity increased with increasing phosphor content.

\section{Conclusions}

The crystallization, microstructure, and properties of phosphor-in-glass ceramic aggregates were studied in this research. The presence of a large amount of $\mathrm{SrAl}_{2} \mathrm{O}_{4}$-based could promote the amorphous structure of glass and inhibit the crystallization of glass. The resultant aggregates could emit their glow and release their stored light energy after the light source was removed. This self-emitting material could be beneficial for lighting outdoor landscape architects such as walkways, pathways, and patios.

\section{Data Availability}

The data is available on request.

\section{Conflicts of Interest}

The authors declare that there is no conflict of interest regarding the publication of this paper.

\section{Acknowledgments}

The authors wish to thank the Department of Materials Science and Engineering, Faculty of Engineering and Industrial Technology, Silpakorn University, for supporting and encouraging this investigation. We would like to express our gratitude to Jirawan Kornsawat, Wannapha Nakowong, and Wannipha Klinjan for their contributions to this work.

\section{References}

[1] E. Bernardo, L. Esposito, E. Rambaldi, and A. Tucci, "Recycle of waste glass into "Glass-Ceramic Stoneware"," Journal of the American Ceramic Society, vol. 91, no. 7, pp. 2156-2162, 2008.

[2] R. D. Rawlings, J. P. Wu, and A. R. Boccaccini, "Glassceramics: their production from wastes - a review," Journal of Materials Science, vol. 41, no. 3, pp. 733-761, 2006.

[3] S. Kaur, A. S. Rao, M. Jayasimhadri, V. V. Jaiswal, and D. Haranath, " $\mathrm{Tb}^{3+}$ ion induced colour tunability in calcium aluminozincate phosphor for lighting and display devices," Journal of Alloys and Compounds, vol. 826, article 154212, 2020.

[4] S. Pimputkar, J. S. Speck, S. P. DenBaars, and S. Nakamuram, "Prospects for LED lighting," Nature Photonics, vol. 3, no. 4, pp. 180-182, 2009.

[5] B. He, Y. Gao, L. Qu, K. Duan, W. Zhou, and G. Pei, "Characteristics analysis of self-luminescent cement-based composite materials with self-cleaning effect," Journal of Cleaner Production, vol. 225, pp. 1169-1183, 2019.

[6] D. Zhang, W. Xiao, C. Liu et al., "Highly efficient phosphorglass composites by pressureless sintering," Nature Communications, vol. 11, no. 1, article 2805, 2020.

[7] J. Park, J. Kim, and H. Kwon, "Phosphor-aluminum composite for energy recycling with high-power white lighting," Advanced Optical Materials, vol. 5, no. 19, article 1700347, 2017.

[8] Y. Pan, F. Zhu, J. Fan et al., "Investigation of mechanical properties of silicone/phosphor composite used in light emitting diodes package," Polymers, vol. 10, no. 2, p. 195, 2018.

[9] T. Hu, L. Ning, Y. Gao et al., "Glass crystallization making red phosphor for high-power warm white lighting," Light: Science \& Applications, vol. 10, no. 1, p. 56, 2021.

[10] V. Loryuenyong, J. Kornsawat, W. Nakhowong, W. Klinjan, and A. Buasri, "The temperature-dependent structural and optical properties of $\mathrm{SrAl}_{2} \mathrm{O}_{4}$-based phosphor," IOP Conference Series: Materials Science and Engineering, vol. 965, article 012028, 2020. 
[11] N. Hisham, M. Zaid, D. I. Saparuddin et al., "Crystal growth and mechanical properties of porous glass-ceramics derived from waste soda-lime-silica glass and clam shells," Journal of Materials Research and Technology, vol. 9, no. 4, pp. 92959298, 2020.

[12] T. K. Aboud, S. Leszek, and S. Marcin, "Quartz crystallization in soda-lime-silica glass," Optica Applicata, vol. 35, pp. 829836, 2005.

[13] J. Wu, C. Lin, J. Liu et al., "The effect of complex nucleating agent on the crystallization, phase formation and performances in lithium aluminum silicate (LAS) glasses," Journal of Non-Crystalline Solids, vol. 521, article 119486, 2019.

[14] L. F. de Lima, J. E. Zorzi, and R. C. D. Cruz, "Vitroceramica basaltica: una breve revision," Boletín de la Sociedad Española de Cerámica y Vidrio, 2020.

[15] K. M. Knowles and R. P. Thompson, "Growth of devitrite, $\mathrm{Na}_{2} \mathrm{Ca}_{3} \mathrm{Si}_{6} \mathrm{O}_{16}$, in soda-lime-silica glass," Journal of the American Ceramic Society, vol. 97, no. 5, pp. 1425-1433, 2014.

[16] H. Yoshida, S. Fujino, and T. Kajiwara, "Afterglow luminance property of phosphorescent phosphor $\mathrm{SrAl}_{2} \mathrm{O}_{4}: \mathrm{Eu}^{2+}, \mathrm{Dy}^{3+}$ glass composites," Journal of the Ceramic Society of Japan, vol. 118, no. 1381, pp. 784-787, 2010.

[17] P. Roldán Del Cerro, T. Salminen, M. Lastusaari, and L. Petit, "Persistent luminescent borosilicate glasses using direct particles doping method," Scripta Materialia, vol. 151, pp. 38-41, 2018.

[18] C. Thieme, K. Thieme, and T. Hoche, "Tunable pore size in diopside glass-ceramics with silver nanoparticles," CrystEngComm, vol. 22, no. 12, pp. 2238-2246, 2020.

[19] T. Nakanishi, "Preparation of europium-activated glass composites using the frozen sorbet technique," Journal of the Ceramic Society of Japan, vol. 123, no. 1441, pp. 862-867, 2015.

[20] L. Xu, P. Sun, X. Chen, P. Zhai, and W. Zhu, "Facile hydrothermal-thermal conversion synthesis of $\mathrm{CaSiO}_{3}$ nanowires as promising structure and function integrated photoluminescent host candidate," Chinese Chemical Letters, vol. 30, no. 1, pp. 171-174, 2019. 